\title{
RELAÇÃO ENTRE PARLAMENTOS: ESTUDO SOBRE O CENTRO DE APOIO ÀS CÂMARAS DA ASSEMBLEIA LEGISLATIVA DE MINAS GERAIS
}

\author{
RELATIONSHIP BETWEEN PARLIAMENTS: STUDY ON THE CENTER OF \\ SUPPORT TO THE CHAMBERS THE LEGISLATIVE ASSEMBLY OF MINAS \\ GERAIS
}

\begin{abstract}
RELACIÓN ENTRE LOS PARLAMENTOS: ESTUDIO EM EL CENTRO DE APOYO DE LA CÁMARA PARA LA ASAMBLEA LEGISLATIVA DEL MINAS GERAIS
\end{abstract}

\author{
Bruno Lazzarotti Diniz Costa ${ }^{1}$ \\ Taíse Leal Lima ${ }^{2}$
}

\begin{abstract}
Resumo: O estudo visa compreender a relação entre a Assembleia Legislativa de Minas Gerais (ALMG) e os parlamentos municipais, por meio do Centro de Apoio às Câmaras (Ceac). Nesse intuito, analisa a criação, a institucionalização e a atuação do Ceac diante do processo de desenvolvimento institucional da ALMG e das relações federativas pós-Constituição Federal de 1988. Para tal, o trabalho realizou investigação qualita tiva, abordagem explora tória, com pesquisa bibliográfica, documentale estudo de ca so. A pesquisa conclui, em linhas gerais, que o Ceac busca contribuir para o aprimoramento das atividades legislativas municipais e se constitui como interface de entrada de informação dos parlamentos locais.
\end{abstract}

Palavra-chave: Federalismo; Poder Legislativo; Cooperação; Legislativos estaduais; Legislativos municipais.

\begin{abstract}
The study aims to understand the relationship between the Legislative Assembly of Minas Gera is (ALMG) and the municipal parliaments, through the Center of Support to the Chambers (Ceac). In this regard, it analyzes the creation, institutionalization and performance of Ceac, in view of the institutional development of the ALMG and federal relations after the Federal Constitution of 1988. In order to do this, the work carried out qua lita tive research, explora tory a pproach with bibliogra phical research, documentary and case study. The research concludes, in general terms, that Ceac seeks to contribute to the improvement of municipal legislative activities and constitutes an interface for the input of information from local parliaments.
\end{abstract}

Keywords: Federalism; Legislative; Cooperation.

Resumen: Este estudio como objetivo comprender la relación entre la Asamblea Legislativa de Minas Gerais (ALMG) y los parlamentos municipales, a través del Centro de Apoyo a las Cámaras (Ceac). Con este fin, a naliza la creación, la institucionalización y la acción de Ceac a la luz del proceso de desarrollo institucional de la ALMG y las relaciones federativas después de la Constitución Federal de 1988. Para ello, el trabajo realizó investigación cualitativa, enfoque exploratorio, con investigación bibliográfica, documentaly estudio de casos. La investigación concluye, en términos generales, que el Ceac busca contribuir a la mejora de las actividades legislativas municipales y constituye una interfaz para la entrada de información de los parlamentos locales.

\footnotetext{
${ }^{1}$ Doutor em Ciências Humanas: Sociologia e Política pela UFMG, pesquisador e professor da graduação e mestrado em Administração Pública da Escola de Governo da Fundação João Pinheiro. Email: bruno.diniz@fjp.mg.gov.br. Orcid iD: http://orcid.org/0000-0001-5972-4175

${ }_{2}^{2}$ Mestre em Administração Pública pela Fundação João Pinheiro (FJP). Graduada em Ciências do Estado pela Universidade Federal de Minas Gerais (UFMG). Email: taise_leal@hotmail.com Orcid iD: https://orcid.org/00000002-1111-0980
} 
Palabras clave: Federalismo; Legislativo; Cooperación.

\section{Introdução}

Este estudo insere-se no contex to de mudanças nas relações entre os entes federativos, com ênfase no Poder Legislativo. Nesse cenário, pontua-se que a Constituição Federal de 1988 CF 88 - acarretou modificação significativa no desenho da Federação brasileira ao garantir aos municípios status de ente federativo e assegurar "aos entes federativos descentrais o status privilegiado da autonomia política" (ZIMMERMANN, 2005, p.15). Contudo, a descentralização, ao ampliar a competência direta dos municípios em áreas que eram de responsabilidade do governo estadual ou federal, desencadeou uma série de desafios, visto a acentuada heterogeneidade entre os entes e a limitada capacidade institucional da maioria dos municípios brasileiros (VELOSO, 2011; SOUZA, 2005). Dessa maneira, observa-se que a baixa capacidade dos governos locais é um desafio para o equilíbrio federativo.

Dentro dessa perspectiva, apesar do papel essencial das Câmaras municipais para viabilizar o atendimento das demandas da população, devido a maior aproximação entre os parlamentares e os cidadãos (ILB, 2016), o Legislativo municipal enfrenta entraves institucionais para o cumprimento de suas atribuições. Assim, não obstante tal discussão se concentrar, majoritariamente, no Poder Executivo, o recente arranjo federativo também impactou as relações no Poder Legislativo. Com efeito, as desigualdades e a reduzida capacidade institucional da maioria dos municípios repercutem na qualidade das funções desempenhadas pelas Câmaras municipais (SILVA, 2014; RAUPP; PINHO, 2011). Em decorrência, a cooperação federativa, assim como ocorre no Executivo, tem sido tendência no Legislativo, por intermédio de redes institucionais que fortalecem o Parlamento brasileiro (RIBEIRO, 2010).

Diante desse contexto, o estudo visa compreender a relação entre a ALMG e os parlamentos municipais, por meio do Centro de Apoio às Câmaras. A escolha da Assembleia de Minas é motivada pelo seu nível diferenciado de desenvolvimento institucional em relação as demais Casas legislativas, sendo a instituição referência nacional (ANASTASIA, 2001; ANASTASIA; SANTOS, 2016; QUINTÃO, 2015; DULCI, 2016; FARIA; DULCI, 2005; COSTA, 2005). Nesse cenário, pontua-se o papel do Ceac para o desempenho das atribuições das Casas legislativas mineiras com público direto composto por 8.481 vereadores (TRE-MG, 2016) e servidores de Câmaras, bem como pelo Parlamento estadual. Destaca-se que o órgão visa aprimorar as atividades legislativas municipais ao mesmo tempo em que se constitui como interface de entrada de informação para a Assembleia de Minas.

Nesse cenário, por meio da abordagem institucionalista, busca-se compreender o desenvolvimento institucional da ALMG (ANASTASIA, 2001; DULCI, 2016) e sua implicação na criação do Ceac. A princípio, observa-se que a ALMG ao estabelecer relações como ambiente, realiza processos intencionais que modificam sua estrutura organizacional e, posteriormente, a 
instituição molda o ambiente ao ampliar sua influência sobre o meio de outras organizações. Desse modo, a trajetória de desenvolvimento institucional da ALMG, caracterizada por atividades voltadas para o fortalecimento das capacidades legislativas, é conduzida pela concepção de influência do ambiente (PERROW, 1972) e pela perspectiva de mudança intencional (CAMPBELL, 2007). Assim, apresenta-se o processo de desenvolvimento institucional que a ALMG vivenciou ao longo das últimas décadas e sua proximidade com os agentes municipais, especialmente os vereadores. Tal aproximação torna-se ainda mais evidente no processo de interiorização daALMG, que estende diversas ações no interior do Estado, visando, dentre outros, o fortalecimento do poder municipal (COSTA, 2005; FARIA; DULCI, 2005). Nesse contexto, ao implementar seu processo de interiorização, a ALMG ampliou a parceria com as Câmaras municipais e trouxe demandas variadas para processamento interno, que culminou na criação um espaço institucional de relacionamento com as Casas municipais (ALMG, 2006).

Em síntese, o Ceac, órgão do Poder Legislativo mineiro, inscreve-se no cenário de mudança nas relações entre os entes federativos e na trajetória de desenvolvimento institucional da ALMG. Nesse contexto, elegeu-se como objetivo central: analisar a criação, a institucionalização e a atuação do Ceac, diante do processo de desenvolvimento institucional da Assembleia Legislativa de Minas Gerais e das relações federativas pós-Constituição Federal de 1988.

O artigo está estruturado da seguinte forma: a primeira seção "Poder Legislativo Municipal e Capacidade institucional" traça o papel do Município decorrente da reformulação constitucional das relações entre os entes federativos, bem como aponta que a limitadacapacidade institucional reflete em entraves para o desempenhodas atribuições do Legislativo municipal. Por sua vez, na segunda “Assembleia Legislativa de Minas e o ambiente institucional”, expõe a singularidade do desenvolvimento institucional da ALMG e sua capacidade de influenciar o ambiente parlamentar. A seção seguinte, "Estudo de caso: Centro de Apoio às Câmaras da ALMG" discorre sobre o contexto de criação, o processo de institucionalização do Ce ac e sua atuação. Por último, "Considerações Finais".

\section{Metodologia}

No que tange aos procedimentos metodológicos, o presente estudo pode ser classificado como qualitativo, com abordagem exploratória, por meio de estudo de caso. Esta pesquisa qualitativa analisa o CEAC embasada nos documentos institucionais da ALMG, não sendo utilizadas informações oriundas das câmaras municipais. Dentro dessa perspectiva, o estudo desenvolvido insere-se no âmbito das pesquisas exploratórias, uma vez que essas são realizadas com o objetivo de "proporcionar visão geral acerca de determinado fato", em especial quando "o tema escolhido é pouco explorado e torna-se difícil sobre ele formular hipóteses precisas e operacionalizáveis" (GIL, 2008, p. 27). 
Observa-se que para subsidiar a coleta de dados foram utilizadas pesquisa bibliográfica e documental, bem como entrevistas semiestruturadas com os cinco servidores efetivos que, no momento do estudo, compunham o corpo técnico do Ceac, posteriormente identificados de 1 a 5. Os profissionais vinculados ao órgão são ocupantes de cargos de nível superior nas áreas de comunic ação - relações públicas e jornalismo - e direito, sendo o quadro composto por um homem e quatro mulheres. Foram entrevistados quatro servidores concursados na carreira de Analista Legislativo Relações Públicas e um servidor Analista Legislativo Consultor Legislativo da área Direito Administrativo e Constitucional, e pontua-se que alguns entrevistados integram o Ceac desde sua criação. Os encontros presenciais ocorreram no local de trabalho dos entrevistados, entre os meses de outubro a dezembro de 2018, e foram gravadas com o livre consentimento dos participantes. As transcrições mantiveram a literalidade das falas dos entrevistados, inclusive com as peculiaridades que a oralidade implica.

Por fim, cabe mencionar a utilização de informações oriundas de fontes estatísticas, de documentos legais e dos Relatórios de Atividade da ALMG (entre 2006 e 2019). Ademais, utilizou-se também informações institucionais autorizadas pela Assembleia de Minas, mediante solicitação intermediada pelo Ceac, como, por exemplo, a pesquisa de reputação da ALMG e as demandas ao Ceac registradas no Sistema de Integração com o Cidadão da ALMG.

\section{Poder Legislativo Municipal e Capacidade Institucional}

O Município é um dos atores centrais na federação brasileira, dado que o processo de descentralização da CF 88 reformulou as relações entre os entes federativos e elevou os municípios ao status de entefederado (MEIRELLES, 1998). Com efeito, ao novo ente, apesardas profundas heterogeneidades e distintas capacidades de atuação, são atribuídas diversas competências constitucionais. Dessa maneira, Bonavides (2016, p. 352) afirma que a autonomia municipal atribuída pela CF 88, configura-se o mais considerável avanço de proteção e abrangência já recebido em todas as épocas constitucionais, o que evidencia maior valorização dos municípios.

O advento da CF 88 redefiniu as atribuições do governo local, resultando na expansão de suas responsabilidades e no surgimento denovas demandas para a estrutura mu nicipal (VELOSO, 2011). Dessa maneira, a descentralização política ampliou as competências municipais, no entanto, desencadeou uma série de desafios. Nesse contexto, cabe ressaltar que "a capacidade dos governos locais de implementar políticas e de arrecadar recursos próprios é altamente diferenciada" (SOUZA, 2005, p. 116). Assim, há diferentes capacidades dos govemos subnacionais, devido às enormes desigualdades financeiras, técnicas e de gestão entre os entes (SOUZA, 2005).Em decorrência, após a redemocratização as Câmaras municipais também foram dotadas de maiores poderes e independência frente ao período anterior (SILVA, 2014).

Nesse cenário, apesar das discussões se concentrarem majoritariamente no Executivo, o 
recente arranjo também impactou as relações no Poder Legislativo. Assim, percebe-se que as desigualdades e a limitada capacidade institucional dos municípios repercutem na qualidade das funções desempenhadas pelas Câmaras municipais. Cabe observar que o Legislativo municipal desempenha diversas funções, além de representar a população, como, por exemplo, a elaboração das leis, a fiscalização da administração pública e a atividade político-parlamentar (RESENDE, 2015). Nesse sentido, as atribuições das Câmaras municipais podem ser classificadas dentro de cinco funções básicas: legislativa, meramente deliberativa, fiscalizadora, julgadora e organizativa. No entanto, "não há uma separação estanque entre as funções: em uma mesma ação do Parlamento, podemos reconhecer o desempenho de mais de uma função" (RIBEIRO, 2012, p. 23).

Isto posto, observa-se que assim como a gestão local é marcada pela heterogeneidade e limitada estrutura institucional na maioria dos municípios, o mesmo acontece nos legislativos municipais, com ênfase para suas fragilidades peculiares. Em decorrência, percebe-se que a deficiente capacidade institucional das Câmaras municipais compromete o desempenho de suas funções. Assim, os poucos estudos realizados sobre o Legislativo municipal apontam para características relacionadas à baixa capacidade de legislar e atuação fraca diante de um Executivo forte (RAUPP; PINHO, 2011). Ademais, percebe-se, no processo de integração dos poderes, a reduzida capacidade das Câmaras municipais para definir o processo decisório local e a autonomização do executivo em relação ao legislativo (KERBAUY, 2005). Com efeito, a troca de favores é característica marcante nas relações entre os poderes municipais, visto que na tentativa de adquirir recursos políticos, os vereadores assumem comportamento colaborativo e obediente em relação ao Executivo, transformando o Legislativo em "poder subserviente" (RAUPP; PINHO, 2011, p. 125). Silva (2014, p. 199) afirma que "se o Poder Legislativo age como um carimbador dos atos do Poder Executivo, não é em razão da força deste último, mas de sua própria fraqueza".

Dentro dessa perspectiva, apresentam-se alguns traços do perfil das Câmaras municipais diagnosticado pelo Instituto Legislativo Brasileiro (2012), como: 89\% das Casas legislativas municipais demandam pela revisão/ atualização do regimento interno; apenas 33\% possuem registro informatizado de tramitação das proposições legislativas; $30 \%$ não disponibilizam gabinetes individuais para os parlamentares; e $76 \%$ não contam com biblioteca legislativa. Ademais, 52,3\% dos parlamentos municipais não disciplinam o acesso aos documentos, informação que revela grau de institucionalização mínimo da Câmara (RIBEIRO, 2010, p. 133). Ainda, pontua-se que as Câmaras municipais brasileiras possuem estrutura desigual, no entanto o quadro geral é de "parca profissionalização do Legislativo" (SILVA, 2014, p. 21). Nesse cenário, Silva (2014, p. 24) também aponta que a baixa profissionalização das Casas legislativas municipais implica que as condições de trabalho dos legisladores e assessores "estão longe das ideias", por exemplo, na maior parte dosmunicípios os vereadores não contam com computadores 
para executar suas funções. Outro aspecto pertinente é o vínculo dos servidores das Câmaras municipais, $29 \%$ ef etivos e $71 \%$ comissionados, ou seja, a maior parte do corpo funcional não possui vínculo permanente, fator que pode dificultar o aprendizado institucional (ILB, 2012). Nesse cenário, percebe-se que "os legislativos municipais são pouco profissionalizados e carecem de infraestrutura física e humana" (SILVA, 2014, p. 199).

Desse modo, diante da baixa profissionalização e acentuadas distinções em relação às estruturas das Câmaras municipais (SILVA, 2014), assinala-se que as Casas Legislativas têm buscado se organizar em redes, visando a circulação de informação e troca de experiência, por meio, por exemplo, das associações de Câmaras Municipais e do Interlegis (RIBEIRO, 2010, p. 204). Nessa perspectiva, Ribeiro (2010, p. 204) afirma que "da autonomia federativa dos entes políticos não pode derivar o seu isolamento", visto que a federação pressupõe o relacionamento entre duas partes. E continua "esta não é uma tendência apenas dos Parlamentos, mas dos governos, e os Poderes Executivos estão em estágio mais avançado nessa seara", como, por meio dos consórcios em diversas áreas (RIBEIRO, 2010, p. 204).

Desse modo, a cooperação integra a organização entre os entes federados, sendo que “articulações de cooperação horizontais (município-município) e verticais (estado-município, União-estado-município) se tornam necessárias para a viabilidade do desenvolvimento de diferentes políticas públicas" (IBGE/MUNIC, 2016). Assim, uma importante tendência no desenvolvimento institucional das Casas Legislativas tem sido o intercâmbio e ações de cooperação entre eles (INÁCIO; ANASTASIA; SANTOS, 2016).

Nesse cenário, visando reduzir os entraves estruturais e a heterogeneidade das Câmaras municipais, que implicam na qualidade das atividades parlamentares prestadas, os legislativos têm buscado se organizar em redes institu cionais de cooperação. Desse modo, norteada pela tendência de interlocução e cooperação federativa, a AssembleiaLegislativa de Minas Gerais tem as Câmaras municipais "como parceiras privilegiadas no seu processo de interiorização" (RIBEIRO, 2010, p. 204). Logo, ao encontro dessa tendência parlamentar, a ALMG desenvolveu um espaço institucional de relacionamento com os legislativos municipais - Centro de Apoio às Câmaras.

\section{Assembleia Legislativa de Minas Gerais e Ambiente Institucional}

No intuito de delinear o cenário de criação Ceac, inovação institucional da ALMG, observa-se a singularidade do desenvolvimento institucional da Casa legislativa mineira (ANASTASIA, 2001; DULCI, 2016), bem como sua capacidade de influenciar o ambiente parlamentar nas relações interorganizacionais. Nesse sentido, orientado pela perspectiva institucionalista clássica de que "as organizações influenciam o ambiente em que vivem, e são influenciadas por ele" (PERROW, 1972, p. 125), evidencia-se que o desenvolvimento da instituição reflete como a Casa legislativa se relacionou e relaciona nesses dois sentidos com seu 
ambiente.

A princípio, pontua-se que dentro da perspectiva institucional, as instituições políticas ou não políticas nunca operam em um vazio, uma vez que estão inseridas ou imersas em uma teia de outras instituições e atores que constituem o seu ambiente. Segundo Perrow (1972, p. 78), todas as organizações têm um ambiente constituído por outras organizações, fornecedores, concorrentes, clientes ou usuários, novas tecnologias, além do complexo meio político e social em que vivem. Ademais, "para qualquer organização, o segmento mais importante do ambiente são as outras organizações" (PERROW, 1972, p. 127). O autor argumenta que a relação das instituições com o ambiente é permeada por instabilidade e tensão, e, por conseguinte, as organizações buscam tentativas de atenuar suas inseguras e incertezas. Além disso, "muitas organizações tentam estabilizar e controlar estas influências ambientais, isto é, tentam lidar com as mudanças de ambiente" (PERROW, 1972, p. 78). Perrow (1972) apresenta, ainda, algumas estratégias distintas de instituições que buscaram reduzir possíveis ameaças do meio ambiente, como, por exemplo, a cooptação, a reciprocidade em ambientes competitivos, a in trodução de inovações constantes, entre outros. Em decorrência, ao estabelecer relações com o ambiente, seja buscando minimizar as ameaças ou ampliar sua influência, as organizações realizam processos que modificam sua estrutura organizacional, tais processos podem resultar em desenvolvimento institucional.

Nesse contexto, o conceito de "desenvolvimento institucional" empregado "refere-se ao conjunto de atividades voltadas para o fortalecimento das capacidades do Poder Legislativo" (UNDP apud MINAS GERAIS, 2009), que pode ocorrer a partir de fatores endógenos à própria Casa ou resultar de fatores exógenos (ANASTASIA; SANTOS, 2016). No caso da ALMG, apresenta-se a combinação entre razões endógenas e exógenas, na qual "ambos se somaram e se complementaram em diferentes níveis de intensidade” (QUINTÃO, 2015, p. 132). Além disso, conforme Anastasia (2009, p. 50), o processo de desenvolvimento institucional realizado pela ALMG foi executado através da combinação entre mudança institucional e ino vaçãoinstitucional. Dessa maneira, algumas práticas decorrentes do seu desenvolvimento institucional podem ser classificadas em mudança institucional, como a Comissão de Participação Popular, e outras como inovações, por exemplo, os seminários legislativos e os fóruns técnicos, entre outros (ANASTASIA, 2009, p. 50).

Cabe pontuar que a mudança intencional, tida como "esforço deliberado para reorganizar ou de outra forma modificar instituições já existentes" (CAMPBELL, 2007, p. 7), da ALMG ocorre no cenário desafiador de assimetria informacional em relação ao Executivo (MADUREIRA, 2009; DULCI, 2016), crise de representatividade (ANASTASIA, 2001), mudanças no contexto da redemocratização e as novas demandas da sociedade (OLIVEIRA, 2009; DULCI, 2016). Desse modo, a Assembleia mineira realiza uma leitura diferenciada do momento político-institucional e empreende a reestruturar a Casa, ou seja, "escolhe" efetuar 
mudanças institucionais (ANASTASIA, 2001). Assim, para Quintão (2015, p. 132), as inovações da Casa são expressão de certos atores orientados para operar mudanças institucionais e adequar essa instituição às exigências do momento político.

Com efeito, Anastasia (2001) afirma que a ALMG construiu importantes traços distintivos dos demais legislativos estaduais, com destaque para a complexidade da organização interna da instituição resultante da reforma administrativa promovida nas décadas de 1980 e 1990, bem como a criação dos mecanismos institucionalizados de interlocução com a sociedade. Essa modernização institucional da ALMG indica um "reordenamento dos trabalhos sob a ótica informacional", visto como importante passo para fortalecer o Parlamento (SILAME, 2009).

Percebe-se que tais inovações institucionais transformaram o perfil da Assembleia de Minas, acarretando a reconstrução de sua imagem pública e colocando-a na vanguarda das assembleias do Brasil (OLIVEIRA, 2009, p. 12). Ademais, em 2009, nota-se o segundo momento emblemático de sua trajetória institucional, no qual a Assembleia mineira repensa seu papel no contexto de novos desafios e das tendências parlamentares em andamento no Brasil e no mundo, por meio do Direcionamento Estratégico 2010-2020 (MINAS GERAIS, 2010). Destaca-se que, dentre seus objetivos, o Direcionamento elenca o compromisso de "intensificar a articulação com as Casas legislativas" (MINAS GERAIS, 2010), tal aspecto vai ao encontro da atuação do Centro de Apoio às Câmaras.

Paralelamente, percebe-se, ao longo dos anos postura proativa da Casa, bem como a tentativa de interiorização e aproximação com parlamentos municipais, dado que a Assembleia também constitui e influencia o ambiente de outras organizações. Tal atuação pode ser inserida dentro da tendência atual de "interlocução interinstitucional" entre os parlamentos democráticos, favorecendo a ampliação das capacidades institucionais (INÁCIO; ANASTASIA; SANTOS, 2016).

No entanto, observa-se o desafio do Parlamento estadual para ampliar seu protagonismo frente as implicações do arranjo federativo brasileiro. Postoque, conforme a CF 88, a competência legislativa estadual é exercida quase sempre "em caráter complementar e supletivo", dado a concentração de atribuições na esfera da União e a ampliação das competências municipais (FLEURY, 2009, p. 35-36). Com efeito, a combinação entre competências estaduais residuais e ampliação das iniciativas do Executivo no processo legislativo, redefiniu o âmbito de atuação dos Parlamentos estaduais. Nesse cenário, Fleury (2009, p. 31) afirma que "os eventos de interlocução com a sociedade constituem uma das mais significativas e importantes (talvez a principal) formas encontradas pelo Poder Legislativo mineiro para atenuar os rigorosos limites impostos por um modelo constitucional". Assim, deve-se pensar o comportamento proativo da ALMG inserido no contexto de implicações constitucionais para os Legislativos estaduais.

Contudo, pontua-se que as Casas legislativas são instituições dinâmicas e que apesar de suas atribuições constitucionais serem bastante complexas, muitas delas ainda vêm diversificando 
suas formas de atuação (RIBEIRO, 2012, p. 9). Como no caso da ALMG, que tem desenvolvido desde o início da década de 1990 um intenso conjunto de atividades voltadas para a interlocução com os diversos segmentos da sociedade mineira (FLEURY, 2009, p. 32). Nesse contexto, as tendências de mudançasimpactam as interações do Parlamento com a sociedade e demais Poderes (INÁCIO; ANASTASIA; SANTOS, 2016). Ademais, cabe observar que "o desenvolvimento institucional de uma Casa legislativa tem impactos nos seus outputs políticos" (ANASTASIA; SANTOS, 2016, p. 18), logo, o desenvolvimento institucional realizado pela ALMG ao longo das últimas décadas gera implicações na produção de seus resultados.

Esse conceito [outputs políticos] mais alargado pode incluir, também, as iniciativas e atividades de difusão e de indução de "boas práticas" para a sociedade, o governo e outras Casas legislativas, tal como ocorreu com as escolas do Legislativo, com as atividades de a poio às Câmaras Municipais e com outras inovações institucionais desenvolvidas pela ALMG. (ANASTASIA; SANTOS, 2016,p. 20).

Nessa perspectiva, o conceito de outputs do legislativo também comporta as iniciativas e atividades desempenhadas pela Assembleia mineira na difusão e indução de qualificação institucional para outras Casas parlamentares. Dessa forma, Ribeiro (2012, p. 9) salienta que a ALMG possui inúmeras iniciativas para auxiliar os legislativos municipais no processo de modernização. Vê-se, portanto, através desse comportamento da ALMG a construção de um caminho de parceria com os legislativos municipais, propício ao fortalecimento do Parlamento. Contudo, é pertinente destacar que o Parlamento mineiro ao assumir essa postura não está extrapolando as suas funções, mas redefinindo-as, sem contrariar a ordem constitucional (RIBEIRO, 2012, p. 9).

Além disso, no que tange à teia de organizações e atores que a Assembleia de Minas conecta e opera, ressalta-se a relação de proximidade que a instituição vem construindo ao longo dos anos com os agentes municipais, especialmente os vereadores. Pontua-se que tal relação é marcada por processos técnicos e políticos, bem como compreende diversas finalidades, como, parcerias institucionais, eventos de capacitação e também a articulação direta dos vereadores com os Deputados, visto que cada parlamentar mantém contato político com sua base eleitoral. Logo, os vereadores mineiros são importantes atores no ambiente institucional da ALMG.

Assim, visando traçar a articulação dos vereadores mineiros com o Legislativo estadual, apresentam-se dados institucionais disponibilizados pela ALMG. O primeiro diz respeito à declaração de comparecimento de agentes públicos à Assembleia, que demostra intensa interlocução que os agentes municipais vêm estabelecendo com no Parlamento estadual, tendo sido realizadas 56.548 mil declarações, de 2015 a 2018. Contudo, o número de visitas efetivas é provavelmente superior, uma vez que as declarações são facultadas ao agente público e emitidas apenas mediante solicitação (MINAS GERAIS, 2015). O segundo refere-se ao estudo de reputação da Assembleia, que evidencia que entre os diversos públicos com os quais a Casa se 
relaciona - público geral, servidores, deputados estaduais e mundo oficial, representantes municipais e organizações da sociedade civil -, sua reputação é superior dentre os representantes municipais, bem como há positiva associação espontânea desse público específico em relação a Assembleia e alta predisposição a apoiá-la (MINAS GERAIS, 2014).

Ademais, ressalta-se que, ao longo dos anos, a ALMG vem realizando ações de interlocução com distintos segmentos no interior do Estado, ressaltando-se o programa de interiorização, que foi iniciado em encontros esporádicos no intuito de promover mais participação do interior (FARIA; DULCI, 2005, p. 382). Costa (2005, p. 60) observa que "a partir de certo momento, percebeu-se que os mecanismos de participação seriam insuficientes se ficassem restritos à movimentação política da Capital", dada a dimensão do estado de Minas Gerais, especialmente, no contexto desafiador de busca por participação mais ex pressiva de outros atores (INÁCIO; ANASTASIA; SANTOS, 2016). Dentre as modalidades de interiorização, destaca-se o processo de fortalecimento do poder municipal com diversas ações voltadas ao poder local (COSTA, 2005, p. 63). Cabe destacar que essa modalidade de interiorização explicita a influência da Assembleia no ambiente de outras instituições.

Assim, o processo de interiorização da ALMG (COSTA, 2005) deve ser pensado em conjunto com a trajetória de desenvolvimento institucional da Casa ao longo das últimas décadas. De modo que a iniciativa da Assembleia de Minas de levar informação aos parlamentos municipais e difundir qualificação institucional, assenta-se no conceito alargado de outputs político (ANASTASIA; SANTOS, 2016). Ademais, pontua-se que a mudança desencadeada propiciou maior interlocução interinstitucional e ganhos de informação para a ALMG.

Com efeito, o ambiente influenciou as mudanças da Assembleia mineira, bem como a instituição constitui o ambiente de outras organizações. No primeiro momento, percebe-se que os desafios no ambiente institucional da Assembleia resultaram na tentativa da Casa de "reagir", resultando em sua mudança intencional. E, posteriormente, à medida que a ALMG se torna um ator com alta capacidade institucional, vê-se seu processo de estabilização e ampliação de sua influência sobre o ambiente, ao aumentar sua proximidade com os legislativos municipais e realizar o projeto de interiorização. Ou seja, a instituição passou a não se limitar apenas em responder as ameaças "de fora para dentro", mas a desenvolver estratégias intencionais para ampliar sua influência. Nesse cenário, em decorrência da mudança institucional da Assembleia de Minas houve ampliação de sua parceria com as Câmaras, especialmente pelo projeto de interiorização que trouxe demandas para processamento da Casa legislativa culminando na criação do Centro de Apoio às Câmaras (MINAS GERAIS, 2006). Assim, a criação do Ceac se inscreve dentro da trajetória de desenvolvimento institucional da Assembleia. 


\section{Estudo de caso: Centro de apoio às Câmaras da ALMG}

O Centro de Apoio às Câmaras instituído pela Deliberação nº 2.381 de 2006, com o propósito de operar como “espaço institucional de relacionamento" (MINAS GERAIS, 2006, art. $1^{\circ}$ ), objetiva facilitar a relação da Assembleia de Minas com as Câmaras municipais, bem como promover a troca de experiências e maior integração entre as Casas legislativas (ALMG, 2019). O contex to de criação do órgão remete ao processo de interiorização da ALMG que ao ampliar a parceria com as Câmaras, em particular por meio de cursos de capacitação para agentes públicos no interior, trouxe demandas variadas para processamento da Casa, que resultaram na criação de um espaço institucional de relacionamento com as Casas municipais (ALMG, 2006).

A princípio, cabe frisar que a instituição já vinha construindo há muitos anos essa relação de proximidade e parceria com os legislativos municipais, por exemplo, ao trocar informações e experiências sobre regimento interno, funcionamento das comissões, entre outros assuntos de interesse dos parlamentos (MINAS GERAIS, 2016a). Como observa um entrevistado "na época que nem existia o Ceac, já existia a demanda dispersa pelos 77 gabinetes da Casa, [...] então essa demanda antes de ser criado o Ceac existia muito nos gabinetes, eles perguntavam como fazia um projeto de lei, entre outros.” (Entrevistado 5).

Nesse contexto, a criação do órgão decorre da tentativa de atender demandas frequentes de vereadores e servidores de Câmaras a diferentes setores da Assembleia, como, dúvidas sobre legislação e processo legislativo (ALMG, 2006). Desse modo, o "Ceac surgiu porque já existia uma demanda das Câmaras à Assembleia que chegavam de forma dispersa, [...] o Ceac assumiu esse papel de coordenar." (Entrevistado 4). Assim, o Ceac busca suprir as demandas e facilitar a logística de informação dentro da ALMG, ao passo que anseia consolidar a parceria entre os legislativos mineiros e aumentar o intercâmbio (ALMG, 2006). Por outro lado, a iniciativa busca propiciar a Assembleia conhecimento sobre a realidade das Câmaras, bem como visa a formação de uma rede que fortalece o Poder Legislativo mineiro (MINAS GERAIS, 2016a).

Ademais, as atividades desenvolvidas pelo Ceac buscam contribuir para a integração entre as Casas legislativas, mas também oferecer atendimento de demandas e compartilhar informações que possam auxiliar os trabalhos municipais. Assim, um entrevistado destaca que “[...] são 853 Municípios, eles não têm esse suporte e é um papel que a Assembleia pode desempenhar, [...] a gente tem um corpo técnico aqui capaz de fazer isso e falta nas Câmaras" (Entrevistado 1). Nesse sentido, outro entrevistado observa: “a nossa perspectiva desde o início foi buscar não assumir uma posição hierárquica em relação as Câmaras, como se aqui tivesse um saber e lá não, então, a gente buscou desde o início trabalhar com essa ideia de rede, uma troca de conhecimento"(Entrevistado 2).

Quanto à institucionalização, o Centro de Apoio às Câmaras possui estrutura permanente, sendo que "o trabalho é constante, continuado, persistente" (Entrevistado 2). Para tal o Ceac possui instalação própria na Assembleia, procedimentos compartilhados, bem como equipe 
formada por profissionais de comunicação - relações públicas e jornalismo - e direito (MINAS GERAIS, 2006). Atualmente, o corpo técnico de servidores diretamente vinculados ao Ceac é composto por quatro servidores concursados na carreira de Analista Legislativo Relações Públicas e um servidor Analista Legislativo Consultor Legislativo da área Direito Administrativo e Constitucional.

Outro importante passo rumo a institucionalização do Ceac foi a definição de suas atribuições, visto que a ALMG possui um conjunto de relação com os agentes municipais, sendo a maioria relações eminentemente políticas - representação e apoio. Dessa maneira, o Ceac procurou não competir com as atividades políticas da Casa, posicionando-se como órgão de natureza técnica. Ou seja, as atribuições do Ceac estão desvinculadas da natureza políticopartidária. Ainda, cabe ressaltar que a inserção institucional do Ceac norteia sua finalidade, como expresso na declaração: “[...] acho importante citar também que na estrutura da Assembleia ele [Ceac] está na Diretoria da Comunicação, ele não é um órgão para fazer capacitação, ou ele não está na Consultoria, ele é um órgão de relacionamento." (Entrevistado 4). Conforme a Figura 1, observa-se que o Ceac se encontra na Gerência-Geral de Relações Públicas e Cerimonial, vinculada à Diretoria de Comunicação Institucional, que é responsável, dentre outras atribuições, por gerir ações direcionadas para "a divulgação das atividades do Poder Legislativo, a formação da opinião pública, a construção e o monitoramento da imagem institucional e o estabelecimento de canais permanentes de interlocução"(MINAS GERAIS, 2015). 
Figura 1 - Orga nograma

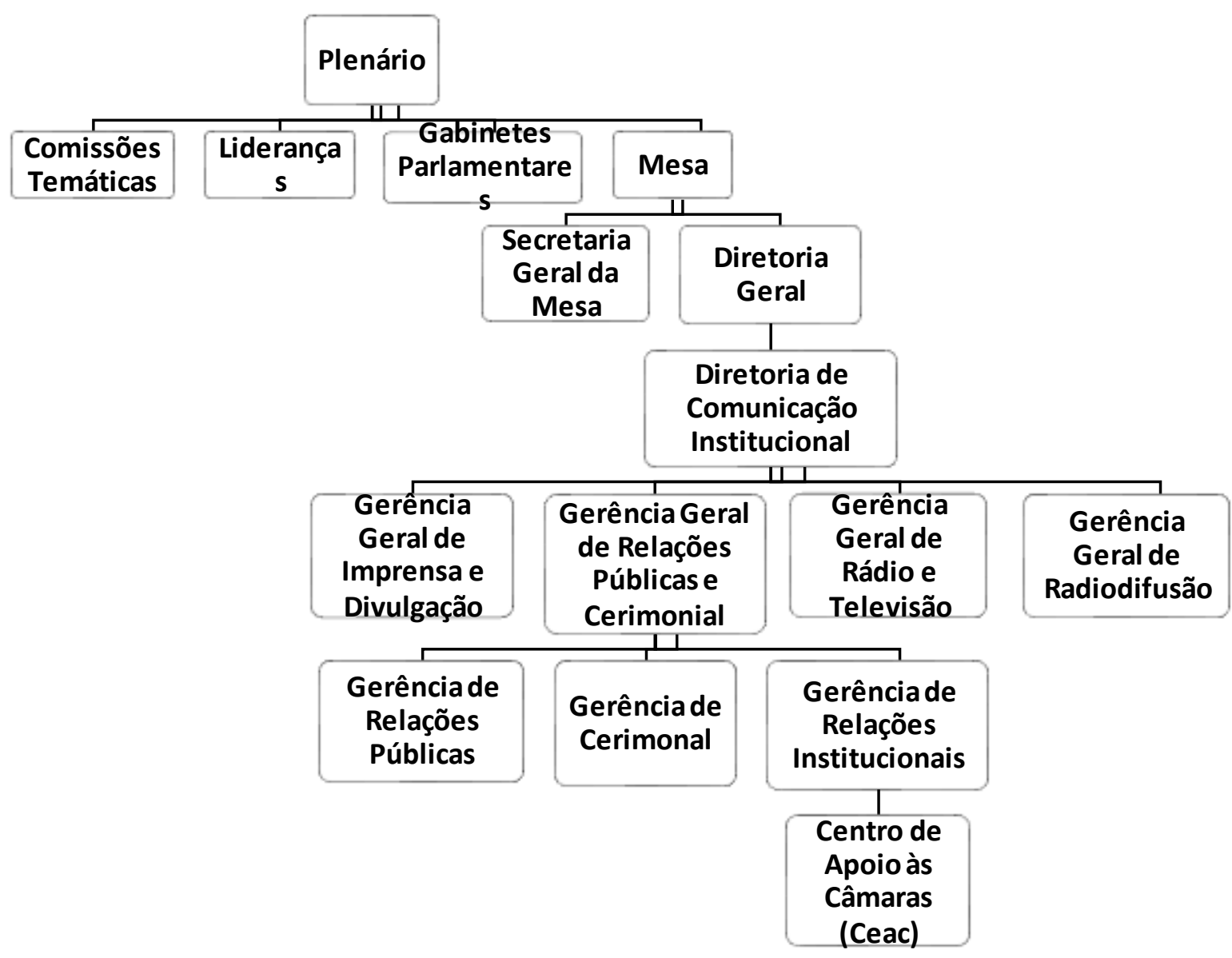

Fonte: Elaboração própria com dados extraídos de ALMG (2019).

No que tange à atuação do Ceac, destaca-se o atendimento às demandas dos legislativos municipais, atividade que tem sido desempenhada desde a criação do órgão, em 2006. Entretanto, apenas após a implementação do Serviço de Interação com o Cidadão (SIC), em 2009, pode-se recuperar e sistematizar os dados, tendo sido cadastradas 2.999 solicitações entre 2009 e 2018 (Gráfico 1). As demandas apresentadas por vereadores ou servidores das Casas legislativas ao Ceac compreendem assuntos relacionados com o processo legislativo; a estrutura e o funcionamento da Assembleia Legislativa; e o exercício das funções do Poder Legislativo (MINAS GERAIS, 2006, art. $4^{\circ}, \S 1^{\circ}$ ). 
Gráfico 1 - Total de demandas 2009-2018

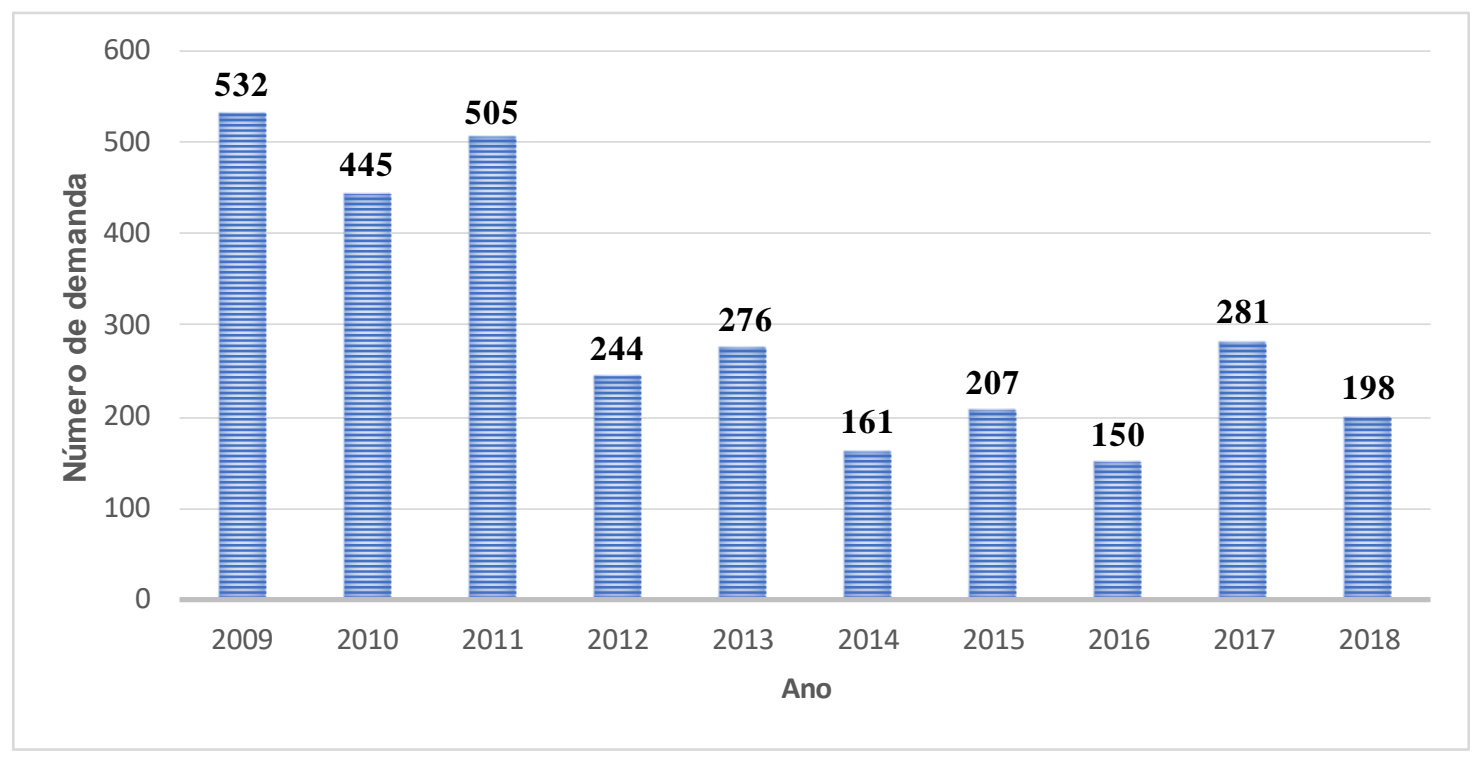

Fonte: Elaboração própria (2019).

O gráfico acima permite observar que os anos de 2009 e 2016 apresentaram maior e menor percentual de demandas por ano, respectivamente, foram registradas $532 \mathrm{e} 150$ solicitações dos parlamentos municipais ao Ceac. Além disso, é evidente a dispersão nos 3 primeiros anos do SIC, com média de 494 demandas anuais, em relação ao período total. Tal desvio, possivelmente, pode ser explicado pelo elevado percentual referente as categorias "dados cadastrais" e "boletim eletrônico" no intervalo, visto que o órgão iniciava o registro das Casas legislativas municipais. Outra informação pertinente refere-se a aparente constância no volume de demandas enviadas entre 2012 e 2018, com oscilação entre 281 e 150 cadastros anuais, bem como média de 216 solicitações por ano. Contudo, destaca-se também que ocorre variação do número de demandas no período devido a mudança de legislaturas, período de atividade legislativa que corresponde ao mandato com duração de 4 anos, visto que no intervalo entre 2012 e 2018 (gráfico 1) os maiores percentuais de solicitações foram registrado em 2013 (276) e 2017 (281), ambos no primeiro ano de legislatura municipal.

Ademais, as demandas registradas no SIC referentes ao Centro de Apoio às Câmaras também são categorizadas. Dessa maneira, a classificação emprega os seguintes grupos: constitucional; organização e funcionamento das Câmaras; processo legislativo; capacitação; agentes públicos; visita técnica; dados cadastrais; boletim eletrônico; outros tipos; e sem registro. Deve-se lembrar que foram encaminhadas 2.999 demandas no período analisado, contudo, a tabela 1 desconsidera as categorias “dados cadastrais" " "boletim eletrônico", visto que esses tipos compreendem cadastro e atualização de dados e se concentram nos primeiros anos do sistema, bem como exclui "outros tipos" e "sem registro", devido a variação injustificada e o desconhecimento das informações que podem ser classificadas nessas categorias. Nessa 
abordagem, a tabela 1 sintetiza a temática de 1.706 demandas, que representam aproximadamente $57 \%$ do total, assim, são apresentadas demandas por tipo - constitucional; organização e funcionamento das Câmaras; processo Legislativo; capacitação; agentes públicos e visita técnica - entre 2009 e 2018.

Tabela 1 - Demandas por tipo 2009-2018

\begin{tabular}{c|c|c|c|c|c|c|c|c|c|c|c}
\hline Tipo de demanda & $\mathbf{2 0 0 9}$ & $\mathbf{2 0 1 0}$ & $\mathbf{2 0 1 1}$ & $\mathbf{2 0 1 2}$ & $\mathbf{2 0 1 3}$ & $\mathbf{2 0 1 4}$ & $\mathbf{2 0 1 5}$ & $\mathbf{2 0 1 6}$ & $\mathbf{2 0 1 7}$ & $\mathbf{2 0 1 8}$ & Total \\
\hline Organização/funcionamento & 61 & 75 & 74 & 27 & 45 & 18 & 38 & 16 & 54 & 13 & $\mathbf{4 2 1}$ \\
\hline Processo legislativo & 59 & 52 & 28 & 15 & 21 & 17 & 22 & 14 & 22 & 23 & $\mathbf{2 7 3}$ \\
\hline Agentes públicos & 62 & 31 & 12 & 18 & 7 & 8 & 4 & 5 & 1 & 5 & $\mathbf{1 5 3}$ \\
\hline Capacitação & 62 & 18 & 24 & 37 & 44 & 13 & 12 & 22 & 39 & 17 & $\mathbf{2 8 8}$ \\
\hline Constitucional & 58 & 44 & 72 & 54 & 34 & 35 & 36 & 36 & 53 & 39 & $\mathbf{4 6 1}$ \\
\hline Visita técnica & 27 & 4 & 17 & 4 & 3 & 5 & 15 & 9 & 14 & 12 & $\mathbf{1 1 0}$ \\
\hline Total & $\mathbf{3 2 9}$ & $\mathbf{2 2 4}$ & $\mathbf{2 2 7}$ & $\mathbf{1 5 5}$ & $\mathbf{1 5 4}$ & $\mathbf{9 6}$ & $\mathbf{1 2 7}$ & $\mathbf{1 0 2}$ & $\mathbf{1 8 3}$ & $\mathbf{1 0 9}$ & $\mathbf{1 7 0 6}$ \\
\hline
\end{tabular}

Fonte: Elaboração própria (2019)

Os dados da tabela 1 demonstram que, dentre as demandas recebidas pelo Centro de Apoio às Câmaras, as principais temáticas abordadas são dúvidas sobre questões constitucionais e sobre organização e funcionamento das Câmaras. Ademais, pontua-se que o art. $4^{\circ}, \S 2^{\circ}$ da Deliberação n ${ }^{\circ}$ 2.381, de 21 de novembro de 2006, determina que "as demandas de atendimento a situações concretas serão respondidas em tese pelo Ceac". Com efeito, as respostas do Ceac apresentam parâmetros de interpretação para os casos solicitados, entretanto não podem manifestar sobre situações concretas das Câmaras municipais, devido a restrições legais e constitucionais. Assenta-se, também, que a Assembleia não possui competência para elaborar parecer ou prestar assessoria jurídica aos legislativos municipais.

Cabe, por fim, assinalar que todas as demandas das Câmaras são cadastradas no SIC e as respostas são elaboradas pelo Ceac, o que contribui diretamente para a disseminação de conhecimento no Legislativo mineiro. No entanto, quando o órgão não possui condições de responder, realiza a facilitação interna de informação na Assembleia, como relata entrevistado:

[...] nesse papel de facilitador, um vereador ou servidor não precisam ficar procurando para onde enviar demandas, não que a gente responda tudo, mas fazemos uma logística da informação dentro da Casa, as vezes a informação está nas Comissões, outras está na área de pessoal [...] (Entrevistado 2)

Além disso, baseado no propósito de contribuir para a formação, atualização e capacitação dos servidores e agentes políticos municipais, a Escola do Legislativo e o Centro de Apoio às Câmaras realizam trabalho conjunto de qualificação, no qual são ofertados cursos, palestras e o programaEncontros com a Política (ALMG, 2019). No que tangeà parceria do órgão 
com a Escola do Legislativo, assinala-se que compete ao Ceac apoiar a promoção das atividades, visto que seu papelé analisar as demandas e mobilizar o público-alvo (ALMG, 2006). Trata-se de iniciativas que contribuem para a capacitação técnica municipal.

No que tange à interiorização das atividades do Ceac, destaca-se, também, as exposições itinerantes com o objetivo de promover a reflexão sobre assuntos inerentes ao Poder Legislativo, bem como temas relevantes de interesse público (MINAS GERAIS, 2016b). Nessa atuação, o Ceac empresta ex posições no formato itinerante e conteúdo de educação paracidadania às cidades no interior de Minas mediante solicitação das Câmaras Municipais, visando a formação política dos cidadãos e aproximação com o Legislativo. Com efeito, o material disponibilizado para exposição propicia oportunidade para as Casas legislativas intensificar o diálogo e a interação com a população.

Ademais, no intuito de incentivar o intercâmbio entre as Casas legislativas mineiras, o Ceac publica o Boletim eletrônico semanal, intitulado Boletim Ceac, cujo objetivo é compartilhar informações e experiências do Poder Legislativo (MINAS GERAIS, 2006, art. $2^{\circ}$, II). Para tal, o Boletim disponibiliza informações coletadas e selecionadas pelo Ceac nos sites da Assembleia, Câmaras municipais, tribunais e outros órgãos. Desse modo, o Boletim Ceac divulga notícias pertinentes ao mandato parlamentar, cursos de capacitação, jurisprudência relevantes ao legislativo municipal, eventos da Assembleia de Minas e das Câmaras, dentre outros (ALMG, 2019). Além disso, o Boletim Ceac abre espaço para que as Câmaras municipais do Estado divulguem ações positivas - inovações democráticas - visando a multiplicação dessa experiência. No entanto, assinala-se que "não se espera algo absolutamente novo, sem precedentes, mas inovador no contexto de cada Câmara" (ALMG, 2019).

A gente percebe que a notícia serve de referência para outra Câmara [...]. Eles vão tomando conhecimento do que está a contecendo de inovação democrática em outras Câmaras Municipais, aquilo serve de estímulo, essas coisas vão crescendo (Entrevistado 4).

O Ceac possui também página eletrônica hospedada no site da instituição (ALMG, 2019) onde são disponibilizados diversos recursos, como: informações sistematiza e atualiza das Casas legislativas; legislações federal e estadual pertinentes as câmaras municipais; banco de jurisprudência, com decisões do Ju diciário que tenham relação comas câmaras municipais; dentre outros. Pontua-se que os serviços disponibilizados pelo site do Ceac auxiliam na promoção de informações para as Casas legislativas municipais, sendo fonte de orientação e consulta.

Diante do exposto, nota-se que o Ceac é o espaço da Assembleia de Minas direcionado para a aproximação da instituição com os legislativos municipais. Trata-se de um órgão técnico que vai ao encontro do objetivo estratégico da ALMG, em especial ao buscar reforçar as redes de interação entre os parlamentos e intensificar o relacionamento do Legislativo estadual com as Câmaras municipais, na "condição de parceiras preferenciais no processo de interiorização das 
ações da Assembleia" (MINAS GERAIS, 2010a).

\section{Conclusão}

Este estudo buscou analisar a relação entre a ALMG e os parlamentos municipais, por meio do Centro de Apoio às Câmaras. A pesquisa demonstra que a cooperação federativa, assim como ocorre no Executivo, tem sido tendência no Legislativo, por intermédio de redes institucionais que fortalecem o Parlamento brasileiro. Por outro lado, apresenta como a Assembleia de Minas lidou com um conjunto de ameaças em seu ambiente institucional, que resultaram na tentativa da Casa de "reagir". E, posteriormente, à medida que a ALMG se toma um ator com alta capacidade institucional, vê-se seu processo de estabilização e ampliação de sua influência sobre o ambiente. Assim, percebe-se que o ambiente impactou e moldou a Assembleia de Minas, que reagiu para minimizar ameaças e, mais tarde, também ampliar sua influência sobre ambiente.

Diante disso, afirmar que a criação do Ceac decorre da modificação da relação entre os entes federativos e do desenvolvimento institucional da ALMG, ao fortalecer suas capacidades legislativas e aproximar sua atuação dos parlamentos municipais, especialmente pelo projeto de interiorização, que trouxe demandas pontuais para processamentoda Casa legislativa. Comefeito, posteriormente, a Assembleia escolhe institucionalizar tais práticas com a criação do Ceac e potencializa essa parceria ao longo dos anos. Ou seja, a criação do Ceac foi uma resposta às pressões do ambiente, bem como uma escolha institucional da Assembleia mineira que, por conseguinte, construiu uma rede de cooperação parlamentar. Portanto, o estudo co mpreende o Ceac como uma inovação institucional que decorre do processo de mudança institucional empreendido pela Assembleia mineira que, no momento seguinte, levou a Casa a constituir e influenciar o ambiente de outras organizações.

No diz respeito à institucionalização do Ceac, o estudo revelou que a definição de suas atribuições foi um passo essencial para o órgão, visto que o Ceac procurou não competir com as atividades políticas da Casa, posicionando-se como órgão de vocação técnica e estrutura permanente. Ademais, o órgão está vinculado a Diretoria de Comunicação Institucional da ALMG, sendo sua finalidade norteada pela inserção institucional, isto é, o Ceac é órgão de relacionamento.

Quanto à sua atuação, percebe-se que as atividades do Ceac são conduzidas pelo objetivo de intensificar a relação entre a ALMG e os legislativos municipais. Dessa maneira, o Ceac colabora para o aprimoramento das atividades legislativas municipais, por exemplo, ao esclarecer as dúvidas encaminhadas pelos parlamentos municipais, bem como ao viabilizar programa de capacitação e educação para a cidadania, como, os Encontros com a Política e as Exposições itinerantes. Ademais, o órgão possibilita um canal de contato entre os parlamentos mineiros, como, por meio da divulgação do Boletim Ceac. Além de se constitui como interface de entrada 
de informação para a Assembleia de Minas, tal atuação pode ser percebida, por exemplo, nos dados sistematizados e atualizados das Câmaras mineiras no site do Ceac.

Por fim, percebe-se que o Ceac é um órgão que busca contribuir para o aprimoramento das atividades legislativas municipais e se constitui como interface de entrada de informação dos parlamentos locais, propiciando ganhos informacionais. Ademais, o Ceac integra a estratégia global da Assembleia de Minas ao tentar aproximar a instituição das Casas legislativas municipais.

Em suma, o estudo almeja ser uma contribuição ao conhecimento do Poder Legislativo, em especial das relações de cooperação entre os entes federativos no âmbito parlamentar. Ademais, assinala-se a carência de estudos sobre o Legislativo, particularmente no âmbito municipal, em detrimento de sua relevância no regime democrático. Nesse contexto, o trabalho fomenta a produção de novas pesquisas e aponta a pertinência de avaliaro Ceac na perspectiva das Câmaras municipais.

\section{Referências}

ANASTASIA, Fátima. Desenvolvimento institucional e representação democrática na ALMG. In: OLIVEIRA, Myriam C. de (org.) A Assembleia de Minas e a construção coletiva de políticas públicas: eventos institucionais, 1990-2009. Belo Horizonte: ALMG, 2009.

ANASTASIA, Fátima. Transformando o Legislativo: a experiência da Assembleia Legislativa de Minas Gerais. In: SANTOS, Fabiano (org.). O Poder Legislativo nos Estados: Diversidade e Convergência. Rio de Janeiro: FGV Editora, 2001. Cap. 1, p. 23-77.

ANASTASIA, Fátima; SANTOS, Manoel Leonardo. Introdução. In: ANASTASIA, F.; SANTOS, M. L (org.). Política e desenvolvimento institucional no legislativo de Minas Gerais. Belo Horizonte: Editora PUC Minas, 2016.

ASSEMBLEIA LEGISLATIVA DE MINAS GERAIS (ALMG). Projeto: Centro de Apoio às Câmaras. Belo Horizonte: Diretoria de Comunicação Institucional, ALMG, 2006.

ASSEMBLEIA LEGISLATIVA DE MINAS GERAIS (ALMG). Centro de Apoio às Câmaras. 2019. Disponível em: www.almg.gov.br/ceac Acesso em: 02 de set. 2019

BONAVIDES, Paulo. Curso de direito constitucional. 31. ed. São Paulo: Malheiros, 2016.

BRASIL. Constituição (1988). Constituição da República Federativa do Brasil. Brasília: Senado Federal, 1988.

CAMPBELL, John L. The rise and transformation of institutional analysis. Department of Sociology Dartmouth College, USA and International Center for Business and Politics Copenhagen Business School, Denmar. 2007

COSTA, Cláudia Sampaio. Construção coletiva: interiorização faz parte do esforço de interlocução com a sociedade e de fortalecimento da democracia. Revista do Legislativo, Belo Horizonte: ALMG, n. 39, p. 58-65, jan./dez. 2005.

DULCI, Otavio Soares. O Legislativo em dois tempos: a modernização da Assembleia mineira e seus antecedentes. In: ANASTASIA, F.; SANTOS, M. L (org.). Política e desenvolvimento institucional no legislativo de Minas Gerais. Belo Horizonte: Editora PUC Minas, 2016. Cap. 2, p. 57-76.

FARIA, Maria Auxiliadora de; DULCI, Otávio Soares. Diálogo com o tempo: 170 anos do 
Legislativo Mineiro. Belo Horizonte: ALMG, 2005. 390 p.

FLEURY, Sabino José Fortes. A participação da sociedade no planejamento estadual: avanços e desafios. In: OLIVEIRA, Myriam C. de (org.) A Assembleia de Minas e a construção coletiva de políticas públicas: eventos institucionais, 1990-2009. Belo Horizonte: ALMG, 2009.

GIL, Antônio Carlos. Métodos e técnicas de pesquisa social. 6. ed. São Paulo: Editora Atlas, 2008 .

INÁCIO, Magna; ANASTASIA, Fátima; SANTOS, Fabiano. O parlamento na atualidade: tendências e inovações. In: ANASTASIA, F.; SANTOS, M. L (org.). Política e desenvolvimento institucional no legislativo de Minas Gerais. Belo Horizonte: Editora PUC Minas, 2016. Cap. 1, p. 33-56.

INSTITUTO BRASILEIRO DE GEOGRAFIA E ESTATÍSTICA (IBGE/MUNIC). Perfil dos municípios brasileiros: 2015. Rio de Janeiro, 2016.

INSTITUTO LEGISLATIVO BRASILEIRO (ILB). O poder legislativo municipal no Brasil: papel institucional, desafios e perspectivas. - Brasília: Senado Federal, 2016. 77 p.

INSTITUTO LEGISLATIVO BRASILEIRO (ILB). Diagnóstico PML: Projeto de Modernização Legislativa. Brasília: Senado Federal, 2012

KERBAUY, M. As câmaras municipais brasileiras: perfil de carreira e percepção sobre o processo decisório local. Opinião Pública, Campinas, v. 11, n. 2, 2005, p.37-58.

MADUREIRA, G. Fábio. Um pacto pela democracia. Revista do Legislativo, Belo Horizonte: ALMG, n. 42, p. 39-45, jan./set. 2009.

MEIRELLES, Hely Lopes. Direito municipal brasileiro. 10. ed., São Paulo: Malheiros, 1998.

MINAS GERAIS. Assembleia Legislativa. Assembleia Legislativa de Minas Gerais: em defesa dos interesses de Minas e dos mineiros. Belo Horizonte: ALMG, 2016a.

MINAS GERAIS. Assembleia Legislativa. Deliberação n. 2.381, de 21 de novembro de 2006. Institui o Centro de Apoio às Câmaras Municipais - CEAC - na Coordenação de Cerimonial e Relações Públicas da ALMG. Boletim da Secretaria, Belo Horizonte, 27 nov. 2006.

MINAS GERAIS. Assembleia Legislativa. Deliberação n. 2.618, de 26 de maio de 2015. Dispõe sobre declaração de comparecimento de agentes públicos à Assembleia Legislativa. Boletim da Secretaria, Belo Horizonte, 06 jul. 2015.

MINAS GERAIS. Assembleia Legislativa. Direcionamento estratégico: Assembleia Legislativa de Minas Gerais, 2010-2020. Belo Horizonte: ALMG, 2010.

MINAS GERAIS. Assembleia Legislativa. Direcionamento estratégico da ALMG 2010-2020. Mapeamento de Tendências: Mudanças e Inovações no Poder Legislativo no Brasil e no Mundo. 2009.

MINAS GERAIS. Assembleia Legislativa. Planejamento Estratégico de Comunicação. Estudo de Reputação da ALMG. Reputation Institute. 2014.

MINAS GERAIS. Assembleia Legislativa. Relatório institucional da Assembleia Legislativa de Minas Gerais 2015. Belo Horizonte: ALMG, 2016 b.

OLIVEIRA, Myriam Costa de. Eventos institucionais e políticas públicas: trajetória e resultados. In: OLIVEIRA, Myriam C. de (org.) A Assembleia de Minas e a construção coletiva de políticas públicas: eventos institucionais, 1990-2009. Belo Horizonte: ALMG, 2009.

PERROW, Charles. Análise organizacional: um enfoque sociológico. Tradução de Sônia Fernandes Schwartz. São Paulo: Atlas, 1972

QUINTÃO, Thales Torres. Fala que eu te escuto? Ouvidorias parlamentares e o seu potencial democratizante: o caso de Minas Gerais. 2015. Dissertação (Mestrado) - Programa de PósGraduação em Ciência Política, Universidade Federal de Minas Gerais, Belo Horizonte, 2015. 
RAUPP, Fabiano Maury; PINHO, José Antônio Gomes de. Construindo a accountability em portais eletrônicos de câmaras municipais: um estudo de caso em Santa Catarina. Cadernos EBAPE. Rio de Janeiro, v. 9, n. 1, p.117 -139, mar. 2011.

RESENDE, Antônio José Calhau de. As funções do Poder Legislativo. Belo Horizonte: ALMG, Escola do Legislativo, 2015.

RIBEIRO, Guilherme Wagner. Funcionamento do poder legislativo municipal. Brasília: Senado Federal, Secretaria Especial de Editoração e Publicações, 2012.

RIBEIRO, Guilherme Wagner. Informação, aprendizagem e inovação nas Câmaras Municipais de Minas Gerais. Tese (Doutorado). Programa de Pós-Graduação em Ciências Sociais, Pontifícia Universidade Católica de Minas Gerais. Belo Horizonte, 2010.

SILAME, Thiago Rodrigues. Comissões permanentes e política de recrutamento nas Assembleias Legislativas de Minas Gerais, Rio de Janeiro e Rio Grande do Sul. 2009. Dissertação (Mestrado). Departamento de Ciência Política, Universidade Federal de Minas Gerais, Belo Horizonte, 2009.

SILVA, Patrick Cunha. O Poder Legislativo Municipal: Estrutura, composição e produção. 2014. Dissertação (Mestrado). Departamento de Ciência Política, Universidade de São Paulo, São Paulo, 2014.

SOUZA, Celina. Federalismo, desenho constitucional e instituições federativas no Brasil pós1988. Revista de Sociologia e Política. Curitiba, n. 24, p. 105-121, jun. 2005.

Tribunal Regional Eleitoral de Minas Gerais (TRE-MG). 2016. Disponível em: http://www.tremg.jus.br/imprensa/noticias-tre-mg/2016/Agosto. Acesso em: 08 de jun. 2019

VELOSO, João Francisco Alves. et. al. Uma visão inicial dos subsistemas da Gestão Pública Municipal. In: VELOSO, J. F. A. et al (Org.). Gestão municipal no Brasil: um retrato das prefeituras. Brasília: IPEA, 2011. Cap. 1, p. 11-40.

ZIMMERMANN, Augusto. Teoria Geral do Federalismo Democrático. 2. ed. Rio de Janeiro: Lúmen Júris, 2005.

Artigo recebido em: 2020-09-22

Artigo reapresentado em: 2020-11-16

Artigo aceito para publicação em: 2020-12-10 